\title{
La ciudad en procesión: estudio sobre traslación de reliquias (Centrado en el ejemplo de San Fructos, patrón de Segovia)
}

\author{
Pablo Sánchez Ferro *
}

\begin{abstract}
RESUMEN
Guardando las cautelas necesarias y desde un "eclecticismo coherente" -perspectiva que conjuga el uso de herramientas teóricas procedentes de diversas disciplinas humanisticas (fundamentalmente de la Antropología, de la Sociología y de la Historia) - el artículo examina un aspecto de la vida social en la época moderna, a saber, el "proceso» de traslación de reliquias. Tal proceso se inscribe, dentro del caso que nos ocupa, en otro de mayor dimensión como es la "construcción" de la figura de un santo patrón, que otorga prestigio e identidad propia a la comunidad a la que "representa". Centrado fundamentalmente en la procesión de traslación de reliquias en un momento del siglo xvi, intenta mostrar cómo en ese momento de reunión de la comunidad se produce un afianzamiento de la identidad y la
\end{abstract}

\author{
ABSTRACT \\ Keeping in mind the necessary \\ precautions and from a "coherent \\ eclecticism" - a perspective which \\ combines theoretical tools from \\ several humanistic disciplines \\ (Anthropology, Sociology and History \\ basically) - \\ the present article explores an aspect \\ of the social life in the Modern Age: \\ the "process" of translation of relics. \\ In this particular case, this process is \\ involved in a larger one: the birth and \\ development of the patron saint figure, \\ who will provide the community he \\ represents with distinction and self- \\ identity. Focused mainly on the \\ procession of translation of relics in the \\ early 16th century, this paper tries to \\ show that, when the community \\ gathers for this purpose, a \\ strengthening of its identity and \\ structure appears. \\ At the same time, we will study the
}

* Universidad Autónoma de Madrid. 
estructura de la misma. Observamos, también, el aspecto devocional que se expresa en torno al santo, por su papel de intercesor del individuo y de la colectividad en la esfera del favor divino. Se concluye con la idea de que entre el santo patrón y la ciudad se produce una comunión de identidades compartidas que da sentido a la existencia de sus gentes. devotion expressed by the community towards the patron saint as the intercessor between the individual and/or the community and God's favour.

Finally we establish that between the patron saint and the city there is a communion of shared identities. To certain extent, this fact gives these citizens a meaning to their existence.

\section{PRESENTACIÓN}

Dentro de los estudios humanísticos, no hay más que diferentes visiones sobre un mismo objeto o realidad, en sentido lato, es decir, del ser y la vida del hombre. Cada cual, al realizar su propio análisis, hará hincapié en unos aspectos, aun sin desestimar otros, según la formación que haya recibido (sociológica, psicológica,...). El caso del historiador no habría de ser diferente. También él tiene una mirada instruida, estc es, educada según unos parámetros teóricos y metodológicos propios de su disciplina, que le encauzan a la hora de abordar sus estudios. No obstante, cada vez es más común abrir los tradicionales campos de visión específicos de cada disciplina para reeducar esa mirada con nuevos enfoques extraidos de otros saberes; de esta forma, dentro de los estudios de la historia han ido apareciendo sectores que se ocupan, con una metodología prestada por otras disciplinas y que es conjugada con la propia, de ámbitos del pasado relativamente nuevos a los que la historiografía tradicional no dedicaba espacio (al menos en nuestro país). Así, han aparecido la historia de la cultura popular, la sociología histórica o la antropología histórica, entre otros tipos de análisis históricos. La utilidad o funcionalidad de este eclecticismo metodológico es tema que ha levantado considerables polémicas y no pocos quebraderos de cabeza a los estudiosos de la historia (bastaría con echar un vistazo sobre los últimos congresos realizados en la Península para constatar este hecho). En nuestra opinión, el sincretismo humanístico puede ser, y de hecho lo es, de gran utilidad para el estudio de ciertas esferas del pasado en las que por la evolución propia de la historiografía no había, como en cierto modo ya se ha dicho, un conjurto de herramientas metodológicas que permitiesen abordar sus estudios con éxito. No obstante, hay que ser cautos a la hora de tomar prestadas 
algunas de esas herramientas, ya que el enfoque del historiador tiene una dirección específica, el estudio del pasado que, eso sí, nos dé una explicación cabal de nuestro presente y que le constriñe a la hora de disponer de ciertas fuentes. Por ejemplo, aun tomando aspectos teórico-metodológicos de la Antropología, es obvio que el historiador no puede contrastar sus conclusiones con el trabajo de campo. Tendrá pues que limitarse a la conclusión comparativa, pero siempre salvando las distancias, tanto temporales como espaciales. Todo lo cual no quiere decir, ni mucho menos, que se produzca una indefinición permanente, sino que se deberá tender al cotejo con diversas fuentes y a la cautela reflexiva. Si se siguen semejantes directrices, poco a poco se podrá establecer (ya existen bastantes logros al respecto) un utillaje propio de la disciplina histórica que amplie en su beneficio los aspectos pretéritos susceptibles de ser aprehendidos (sin entrar en discusiones sobre el grado de objetividad de los mismos), para poder tener una visión más amplia del pasado.

Con el presente estudio esperamos contribuir, aunque sea modestamente, al análisis de las esferas de la historia que nos permitan tener un mayor acercamiento al paisaje social pretérito. Cabría señalar que hemos utilizado en nuestro enfoque un zoom muy potente que nos ha permitido observar un detalle de la realidad social y mental de un grupo humano en un momento muy específico. Esto es en definitiva lo que se ha venido a llamar "microhistoria"; pero, a su vez, hemos amalgamado el estudio antropológico, desde una perspectiva histórica, con el estudio social y de las mentalidades. Puede parecer una mezcla de elementos poco definidos, pero en nuestra opinión nada más distante del collage que este análisis. No deberíamos olvidar que la realidad no es unidimensional, ni ahora ni en el tiempo de nuestros antepasados lejanos, por lo que limitar nuestro encuadre nos habria hecho caer probablemente en el, las más de las veces, empobrecedor determinismo. Sin más dilación, podemos dar paso al examen del tema.

\section{LAS RELIQUIAS ESTÁN VIVAS}

"Llego un pobre a pedir limosna al convento del Aguilera, en ocasion que el portero habia dado toda la limosna â otros pobres que llegaron antes. Viendose despedido, sin limosna, y sin consuelo, se fue al Sepulcro del Santo, y arrojandose sobre el, con grande ansia, y fatiga començô a dar vozes diziendo. O Santo Bendito si vos fuerays uiuo no muriera yo de hambre, ni me fuera sin limosna deste Monasterio. Caso admirable, abriendose luego la sepultura, y alargando el Santo el braço con un pan en la mano se 
Ie dio al pobre, con que remedio su necesidad, y quedo hecho pregonero del milagro"'.

El episodio anterior permite entender que, en ciertos ámbitos y para según qué mentalidades, las reliquias están vivas. Las reliquias asisten a los pobres, sangran - «(...) desseando llevar (Isabel, la Católica) al Rey alguna reliquia del Santo, mando cortarle una mano, de la qual, y del braço, corrio mucha sangre, durando esto por un gran rato. (...)" ${ }^{2}-$, y tienen conciencia y deseos que las determinan -. -(...) auiendo sacado el sancto cuerpo del lugar a donde estaua, y queriendolo lleuar a la lglesia mayor, se hizo immobil. (...) $)^{3}$. Estos testimonios muestran con claridad que para los devotos castellanos de la Edad Moderna las reliquias eran, aunque no lo afirmasen ni tuviesen conciencia de ello, una realidad viviente. La verosimilitud de tal hecho es algo que no importa, o al menos no importa a nuestros efectos, porque lo que verdaderamente parece relevante es que los restos de un santo, sus huesos pero también sus ropas y otros objetos con los que tuvieron algún contacto ${ }^{4}$, necesitan de atención para que sean (para vivir), como si se tratase de un niño recién nacido; o mejor, como un anciano, una persona mayor a la que se deben dar ciertos cuidados porque de lo contrario expira ${ }^{5}$. Así, pues, a las reliquias se les puede atribuir una vida, pero es una vida necesariamente asistida por la comunidad, con su devoción y cuidado, que es el hálito que las perpetúa y dota de identidad, y prestigio. Un prestigio que se inicia con la vida del santo, con los testimonios que de su ejemplar existencia y milagros se van recogiendo, bien por tradición, o por escritos hagiográficos y que, de igual forma, se acrecenta con su muerte; estableciéndose un umbral definitivo en la ca-

1 Daza, A. Excelencias de la ciudad de Valladolid, con la vida, y milagros del Santo Fr. Pedro Regalado, natural de la misma ciudad: uno de los tres fundadores de la Santa Provincia de la Concepcion, de la Regular obseruancia de la Orden de nuestro Serafico Padre S. Francisco. Dirigido al Rey nuestro Señor, don Felipe IIII. Valladolid, impreso por Juan Lasso de las Peñas, 1627. pág. 103. A partir de ahora Excelencias.

Ibidem, pág. 130 bis.

LOBERA, Fr. Athanasio de: Historia de las grandezas de la muy antigüa e insigne ciudad y iglesia de León, y de su obispado, y patron Sant Froylan, con la del glorioso San Atilano. Obispo de Çamora. Editado por Diego FERNANDEZ DE CORDOBA, impresor del Rey, Valladolid, 1596. pág. 152 bis.

4 En Bouza Álvarez, J.L. Religiosidad contrarreformista y cultura simbólica del Barroco. Madrid, C.S.I.C., 1990, podemos leer que, en tiempos de San León, de un paño que habia estado en contacto con el santo brotó sangre cuando fue punzado.

5. CÁtedra Tomás, M., Un santo para una ciudad. Ensayo de antropología urbana. Barcelona, 1997. Se muestra el ejemplo de san Segundo, patrón de Ávila, que perdió la devoción por falta de asistencia (la despoblación de la zona donde se encuentra su ermita, desaparición de la cofradía que mantenía su culto,...). 
nonización, que deposita en el santo una identidad y una dignidad perpetua, al universalizar su figura ${ }^{6}$. Por lo tanto, se puede decir que si los santos son un testimonio de Dios, los devotos son un testimonio de los santos, lo que configura una línea continua que vincula y deriva la gracia divina desde su provisor hasta el humilde cristiano. Pero el prestigio del santo no es inocente, sino que, en el caso de un patrón salpica a la ciudad, dotándola de dignidad y fama en proporción directa a la que tenga éste, su abogado (vg. Asís es conocido por san Francisco; Compostela por Santiago, el patrón que le da su nombre,...). Así nos dice Orche que "Una de las cosas, que más ennoblecen, y hazen famosa una Ciudad, y Prouincia, y aun la que mas la ensalça, es el valor, y calidad de sus naturales. $Y$ assi es cosa clara, y muy llana que la tierra, que produxere mas heroycos, $y$ auentajados hombres en todo genero de virtud, y buenas artes, tendra el primer assiento en los estrados del merecimiento. (...) Y si tan celebre ha sido y es en el mundo el nombre de muchos pueblos pobres y pequeños, solamente por auer nacido en ellos hombres famosos y señalados; que honra, que authoridad, y grandeza se le seguira a la ciudad de Segouia, de ser patria de tres santos hermanos tan celebres y señalados, como San Fructos, San Valentin y Santa Engracia"?. Por lo

6 Del Rio BarRedo, M.J. («Literatura ritual en la creación de una identidad urbana: Isidro, patrón de Madrid". Edad de Oro, XVII, 1988), ve la interacción que se produce entre la creación de la identidad de san Isidro y la configuración de la identidad de la ciudad de Madrid, cuya apoteosis se da con los festejos organizados con motivo de la canonización del santo. En el artículo se muestran las dificultades que implicaba un proceso de canonización, en el que el esfuerzo de la ciudad es indispensable para recabar información sobre la vida del santo, sufragar los costes y realizar la actividad diplomática necesarios. En el caso que nos ocupa, el de la ciudad de Segovia y su patrón, san Fructos, no se llega a la canonización, pero el proceso queda cumplido con la traslación de las reliquias del santo en 1522, desde los Alcázares a la Catedral, entre dos «espacios de poder" (tomo la expresión de CÁTEDRA TOMÁS, M., Un santo para una ciudad, Ensayo de antropología urbana. Barcelona, 1997, pág. 55, que estudia la significación del patronato de san Segundo en Ávila), y no de una localidad a otra, como era lo habitual.

La fiesta de canonización de un santo, 0 , en su defecto, la traslación de sus reliquias y su colocación en su emplazamiento definitivo, se podria considerar, a estos efectos y dentro de esa vida del santo, como el rito de institución que le transfiere un nuevo "status", o legitima y consagra, de forma solemne, una realidad existente (en referencia a su culto). Sigo la idea de rito de institución que Boufdieu, P., "Los ritos como actos de institución", en Pitt-RIvers, J., y Perstiany, J.G., eds., Honor y gracia, Madrid, 1993, utiliza al analizar los ritos de paso. Según dicho autor, estos ritos implican un cambio de "status" de la persona que lo experimenta, accediendo a una nueva situación que le eleva de categoría social, diferenciándole de forma permanente de aquellos otros que, por su condición, no podrán pasarlo. Al transferir esta explicación a los santos, cabe ver una similitud en el caso de los santos escogidos como patronos, y, más aún, en el de los canonizados que, por tal rito, acceden a un "status superior" dentro de la sociedad de los santos (según como la ven los devotos), que, con toda seguridad, hará que aumente su culto.

ORCHE, J de. Historia de la vida del glorioso S. Fructo, patron de la ciudad de Segouia, $y$ de sus hermanos San Valentín y Santa Engracia. Contiene la destuccion de España por los Moros: grandezas y antiguallas de la ciudad de Segovia; con un compendio de los Reyes y Reynas que 
tanto, la ciudad quiere un santo patrón que la dignifique y dote de identidad. Es por esto que la figura del patrón trasciende su sentido de abogado intercesor - un sentido cuya importancia es incuestionable para la mentalidad del devoto que busca y siente (en sus milagros) el amparo de su mediación en la esfera celestial- -, sumándole la cualidad de ser elemento de cohesión de la comunidad urbana, especialmente en las procesiones en que se involucra su presencia, tanto en las de carácter festivo (vg. la traslación de reliquias) como en las de carácter rogativo (buscando su socorro ante alguna amenaza ${ }^{8}$ ). Porque, si bien la procesión es «una asamblea litúrgica en marcha" ${ }^{9}$, donde cada cual siente su religiosidad con una intensidad propia (según la devoción que se tenga por el santo, en el caso de la traslación de reliquias, o de la imagen; lo que es imposible de cuantificar); también es un momento en el que la comunidad se reúne por un interés y devoción comunes ${ }^{10}$ : la figura del santo patrón, en el caso que me ocupa. Pero hay que considerar que en la procesión también se proyecta la imagen que la ciudad quiere dar, y se da, a sí misma, expresando los equilibrios de poder y las funciones de los diferentes grupos, corporaciones e individuos, que la integran ${ }^{11}$.

han Reynado en España, desde que la comenzaron a ganar y restaurar de los Moros. Christoval LASSO VACA, Valladolid, 1610, págs. 1-2). A partir de ahora Historia de la vida del glorioso S. Fructos.

B Por ejemplo ante una epidemia de peste. En el relato de ORCHE (pág. 196 bis) se señala que con motivo de la traslación de las reliquias de los santos patrones de la ciudad cesó un brote de peste, recomendando que en situaciones similares se saquen sus reliquias en procesión. Esto ilustra, por una parte, las propiedades sanadoras y profilácticas que se atribuyen a las reliquias, y, por otro lado, muestra también cómo hay procesiones en las que las reliquias se sacan con un carácter rogativo, pero entiéndase que estas otras procesiones no son asimilables a las de traslación - cuyo carácter es festivo--, que implican un cambio de emplazamiento, sino que se inscriben dentro de lo que podríamos llamar procesiones de intercesión, cuya finalidad no es el traslado mismo de las reliquias (que finalmente volverán al mismo sitio donde se encontraban al salir en procesión), sino procurar la intercesión del santo para conjurar alguna amenaza o mal.

9 Martimort, A. G., La Iglesia en oración. Introducción a la liturgía. Barcelona, 1992. pág. 813.

10 En nuestra opinión, las procesiones de traslación de reliquias tenían la capacidad de fomentar ese sentido de communitas (por el cual un individuo siente intimamente su pertenencia como hombre, como igual a los otros, a la colectividad como orden armónico trascendente, en un sentido interiorizado, implicito) que Victor TURNER señala en su análisis de los ritos de inversión de "status", pero con la diferencia de que en la procesión de traslación no se da una ruptura transitoria e intensa (liminal) de la estructura social (la cual, TURNER, señala como necesaria para mantener el equilibrio del grupo, para fomentar la communitas, al permitir que los que están abajo, puedan estar arriba en un lapso temporal efímero), sino que, al contrario, se produce una reafírmación de la misma, pero con el mismo efecto: mantener la unidad de la communitas. Esto es posible, nos parece, porque la procesión impulsa un sentimiento de humildad piadosa común a todos los individuos asistentes, por lo que aun manteniéndose la estructura jerárquica imperante en la sociedad, incluso con profusión de opulencia, el carácter festivo devocional común iguala y unifica a la ciudad. (TURNER, V. W., «Humildad y jerarquia: la liminalidad de la elevación y de la inversión de status", El proceso ritual. Estructura y antiestructura, Taurus, Madrid, 1988, págs. 170 y ss.).

11 Vid. Supra, n. ${ }^{\circ} 10$. 
Llegados a este punto, lo mejor es pasar a ver cómo en el ejemplo de san Fructos se dan, de forma paulatina, el conjunto de circunstancias que le llevan a la consagración de su patronato, y cómo, en el ejemplo de la traslación de sus reliquias, confluyen esas características de la procesión que aúnan a la ciudad, dotándola de una identidad propia.

\section{VIDA, MILAGROS Y MUERTE DE SAN FRUCTOS, PATRÓN DE SEGOVIA}

En el segundo capítulo de su Historia de la vida del glorioso S. Fructos..., Juan de Orche (Licenciado Lorenzo Calvete, capellán de los Duques del Infantado) sitúa la fecha de nacimiento de San Fructos en el año 642, "Reynando en España Tulca, (...) vigessimo septimo Rey Godo de España" ${ }^{12}$, deduciéndola de la noticia que tiene de la existencia de un epitafio situado en un altar de la Casa y Priorato de $\mathrm{S}$. Fructos que señala la muerte del santo en el año 715, "a las ocho de las candelas de Nouiembres ${ }^{13}$, a la edad de 73 años. De esto se extrae que el glorioso santo vivió en la época de ocupación musulmana de la Península lbérica y en las primerísimas fechas del inicio de la resistencia hispanocristiana, que se iría articulando, desde los primeros años del siglo VIII, en la acción de numerosos grupos diseminados por la franja cántabro-pirenaica. Esta realidad histórica será un elemento determinante en la vida del santo, y en la posterior suerte de sus reliquias.

Aunque los conocimientos referentes a los orígenes de San Fructos presentan cierta vaguedad ${ }^{14}$, se tiene por cierto que "sus padres fueron naturales de la ciudad de Segouia, gente rica y muy principal” ${ }^{15}$, que le

\section{$643)$.}

ORCHE, J. de. Historia de la vida del glorioso S. Fructos..., pág. 4. Se refiere a Tulga (639-

Ibia, pág. 6. En el titulo del epitafio que refiere ORCHE se señala, en referencia a la muerte del santo, que "fue su glorioso tránsito en la era de Cesar de 753. Que es año de Christo de 715 descontados destos los 73 que vivió, vienen a quedar en 642 años». La referencia al mes de Noviembre diverge con la lel considerado mes de la muerte del santo, octubre, que sí señala Diego de Colmenares: Historia de la Insigne ciudad de Segovia y Compendio de las historias de Castilla. Segovia, Academia de Historia y Arte de San Quirce, 1982, (1. ${ }^{a}$ ed. 1633), pág. 170 .

${ }_{14}$ "Escribiremos ahora las vidas de nuestros santos patrones Frutos, Valentín y Engracia, hermanos, que por haber vivido en tiempos tan miserables y alborotados, tenemos de sus cosas menos noticia que deseamos". Diego de Colmenares, Historia de la Insigne ciudad de Segovia y Compendio de las historias de Castilla. Segovia. Academia de Historia y Arte de San Quirce, 1982. (1. ${ }^{\text {a }}$ ed. 1633). (A partir de ahora: Historia de la Insigne ciudad de Segovia...).

15 Historia de la vida del glorioso S. Fructos..., pág. 2. "rico hombre llamauan al que era noble y principal", aclara ORCHE. 
proporcionó una "criança" ${ }^{16}$ basada en santos principios, dándole ejemplo con sus costumbres piadosas y misericordiosas, acordes con los mandatos divinos. Educación que ya encaminaba al niño Fructos hacia una vida cristiana ejemplar, "(p)orque aunque la gracia Divina, es la que cria, y conserva la Santidad en el coraçon, mas mucho importa yrla los niños mirando en las vidas, y costumbres de los padres" 17.

Parece que ya en la niñez Fructos era un muchacho piadoso y muy devoto, especialmente de la Virgen María, a la que dedicaba oraciones "en reconocimiento de vassallage" ${ }^{18}$ y rogándole que "endereçasse sus caminos en servicio de Dios, y salvacion de su alma, y de su mano le pusiesse en el estado que mas le convenia para estos fines" 19. Además, durante su infancia, Fructos oía misa todos los días y practicaba el examen de conciencia antes de dormir. Y como ejemplo precoz de su pureza de espíritu valga señalar que siendo aún infante consigue evitar caer en las tentaciones que el demonio le pone mientras sueña.

Tras la muerte de sus padres, Fructos decide repartir entre los pobres la herencia recibida y marcharse con sus hermanos, Valentín y Engracia, a un rincón aislado en "un desierto peñascoso en la ribera setentrional del rio Duratón (...), distante de nuestra ciudad (Segovia) al norte diez leguas (...) para retiro del mundo y escala del cielo" 20 . Aquí, los hermanos construyen entre las peñas una ermita diferente para cada uno de ellos, donde mantendrán una vida ascética dedicada a la penitencia y acompañada de una gran santidad.

Desde el punto de vista hagiográfico, la vida del santo ha pasado, hasta el momento, del "deseo de santidad" (la infancia piadosa y devota anhelosa de servir a Dios) al "proceso de perfeccionamiento" (retiro y vida eremítica y penitencial), por lo que únicamente le falta cumplir el tercer momento secuencial del proceso de perfeccionamiento espiritual que se da en la vida de un santo, a saber: el éxito, la santidad probada ${ }^{21}$.

\footnotetext{
16 Ibidem, pág. 8.

lbidem, id.

lbídem, pág. 7.

Ibidem, id.

Colmenares, Diego de. Historia de la Insigne ciudad de Segovia..., pág. 168.

Sigo la propuesta definitoria del relato hagiográfico de Bremond, expuesta en Baños $V_{A-}$ LLEJO, F. La hagiografía como género literario en la Edad Media. Oviedo, 1989, pág. 138. Respecto a la santidad probada, se señalan tres momentos: prodigios in vita, muerte, prodigios post mortem. Estos criterios calibradores de la santidad coinciden básicamente con los requerimientos para la canonización establecidos por el Papa Urbano VIII (1623-1644): “(..) all candidates except martyrs must satisfy three general requirements: doctrinal purity, heroic virtue, and miraculous intercession after death.". En WEINSTEIN, D. y BELL, R. M. Saints and society. The two Worlds of
} 
Etapa que en la vida de San Fructos se desarrolla en un momento determinado de su retiro, en el que, debido a la invasión musulmana, numerosas personas acuden a su amparo por temor a la amenaza de posibles razzias. En esta coyuntura se va a producir el famoso milagro de la cuchillada de San Fructos: cuando las escuadras moras se aproximan a las ermitas, Fructos, con el deseo de proteger a las gentes venidas a su refugio, implora a Dios su ayuda, y poniéndose delante de los moros traza una raya con su báculo que, milagrosamente, abre la peña con una profunda grieta que separa y salvaguarda a los cristianos de los musulmanes. Tras este milagro, la intercesión del santo hará que se cumpla otro de carácter menos espectacular, pero de gran peso teológico, ya que reafirma el principio de la transubstanciación. Tal maravilla se produce a raiz de los comentarios de un musulmán que "(...) blasfemó de la santísima Eucaristia, diciendo que los cristianos adoraban imposibles, creyendo que el pan se convirtiese en Dios, y se permitiese comer asi de los hombres como de las bestias, pues si se lo pusiesen en un poco de cebada lo comerian (...)»22. Fructos, "(..) considerando que donde falta el discurso obra la fe, confiando en las promesas divinas consintió en que se hiciese la prueba. $Y$ consagrada una hostia fue puesta sobre un arnero de cebada, y traido un jumento. Habia concurrido al espectáculo número escesivo de cristianos y moros. Frutos y sus hermanos con espíritus fervorosos suplican a Dios glorificase su eterna verdad. Llegó el animal, y en viendo la hostia que sobre la cebada estaba, inclinando la cabeza, se postró en tierra; levantando los cristianos espiritu y voces a Dios, no sólo maravilloso en sus santos, pero reconocido de los animales por su eterno criador» ${ }^{23}$. Estos milagros dan nombre y fama a los hermanos santos,

\footnotetext{
Westertn Christendom, 1000-1700. Chicago, 1982. En una de las obras que he consultado se dice: "Los Milagros que se requieren para canonizar â los Santos, no son los que hazê en vida, (porque aunque entonces estan en gracia de Dios, pueden perderla adelante) sino los que hazen despues de muertos: por ser estos los que comprueuan la Santidad de su vida". DAZA, A., Excelencias... pág. 103. No obstante, no se debe olvidar que existe devoción a santos que no han sido canonizados ( $\mathrm{ni}$ siquiera el santo Regalado estaba canonizado en el momento que Daza, que tiene conocimiento de ello, escribe su obra. Actualmente el Martirologio Romano recoge su fiesta: dia 30 de marzo «en Aguilar de Campoo, en España, san Pedro Regalado, natural de la ciudad de Valladolid, sacerdote de la Orden de Menores y Confesor, restaurador de la disciplina regular en los conventos de España; a quien el Papa Benedicto XIV (1740-1758) puso en el catálogo de los santos". Martirologio Romano. Versión Española ajustada a la edición Vaticana de 1948. Por el P. Valentín M. SÁnchez Ruiz, S.J. Madrid, 1949.). Respecto a la necesidad de que un santo realice milagros tras su muerte para ser tal, cabe señalar que "(u)n mártir queda dispensado de los milagros". En MARTIMORT, A.G., La lglesia en oración. Introducción a la liturgia. Barcelona, 1992; lo que también se puede apreciar en la anterior cita de Weinstein y Bell.

22 Colmenares, D. de, Historia de la Insigne ciudad de Segovia..., pág. 169.

23 Ibid., pág. 169-170.
} 
especialmente a Fructos, el mayor, y el que más claras cualidades taumatúrgicas posee ${ }^{24}$.

Respecto a la muerte del santo se aprecian divergencias en las diferentes hagiografías. Juan de Orche la sitúa en el 25 de octubre del año 715 , tras el padecimiento de unas fiebres que acrecentaron el deseo de Fructos de "llegar al puerto del eterno descanso" ${ }^{25}$. Pero Diego de Colmenares muestra la discrepancia entre fuentes que señalan como fecha de la muerte el año 725, admitiendo la posibilidad del martirio del santo por los moros, frente a las que mantienen la versión de Juan de Orche que, finalmente a ojos de Colmenares, parecen más autorizadas.

Como no se debe olvidar en el análisis que nos ocupa la "suerte" de los hermanos de San Fructos - a los que se consideran también patrones de la ciudad de Segovia (aunque el tiempo los irá dejando de lado frente al afianzamiento del patronazgo de su hermano mayor)-, parece pertinente referir, aunque sea en un ligero esbozo, las circunstancias de su muerte: Valentín y Engracia, una vez muerto su hermano Fructos, se trasladaron a Caballar, pueblo cercano a Segovia, donde continuaron con su vida de ermitaños hasta que fueron martirizados por los musulmanes. Sus cuerpos serian trasladados junto al de su hermano, mientras que sus cabezas permanecerán en Caballar, como reliquias especializadas en procurar las lluvias para el conjunto "de toda la comarca, cuyos pueblos cuando falta agua para los frutos, acuden devotas procesiones a pedir socorro a Dios por intercesion de sus santos, llevando las cabezas en procesión a una fuente que nombran "Santa", porque es tradición constante que fueron echadas en ella cuando los moros las apartaron de sus cuerpos en el martirio. $Y$ certificamos que habiendo concurrido a esto, hemos visto efectos de pluvias admirables en constelación bien contraria, mostrándose Dios piadoso y agregado de la devoción que estos pueblos tienen de sus santos» 26 .

\footnotetext{
24 En COLMEnARES (pág. 168) se refiere un tercer milagro: "En esta altura (se refiere a la situación de la ermita de San Fructos, situada en la parte más alta de la peña a la que se retiraron a vivir los hermanos) se goza y venera hoy una fuente que nombran de San Frutos con tradición de que el santo la brotó milagrosamente con el báculo".

25 ORCHE, J. de. Historia de la vida del glorioso S. Fructos..., pág. 73

26 Colmenares, D de, Historia de la Insigne ciudad de Segovia..., pág. 171. En esta cita se aprecia que el juez de los padecimientos humanos en última instancia es Dios; de forma que, como ha señalado William A. Christian (Religiosidad local en la España de Felipe II, Madrid, 1991) los santos representarán "a la comunidad delante de Dios" en calidad de abogados intercesores; lo cual implica un complejo sistema de clientela, de intercambio de votos y favores, entre la comunidad y sus santos (la limosna, la oración y los votos pueden ser considerados la prima a pagar por los devotos para disponer del auxilio de los santos).
} 


\section{AVATARES EN LA VIDA DE LAS RELIQUIAS DE LOS SANTOS FRUCTOS, CONFESOR, VALENTIN Y ENGRACIA, MÁRTIRES ${ }^{27}$}

Consignar de forma detallada y concienzuda los varios traslados y vicisitudes sufridos por las santas reliquias de San Fructos, San Valentín y Santa Engracia, es una tarea que aquí no es preciso puntualizar en detalle ante la intención final de este estudio, que, como ya se ha dicho, es el análisis de la procesión de traslación de dichas reliquias desde los Alcázares a la Iglesia de Santa Clara (donde, a la sazón, se encontraba la catedral), en el año de 1522. No obstante, ciertas referencias son en más de un punto pertinentes para comprender las circunstancias finales que llevaron a éste último traslado ${ }^{28}$.

Inicialmente, los santos cuerpos y reliquias de san Fructos, San Valentín y Santa Engracia son escondidos "por temor de los Moros, en aquel hueco de la pared de la hermita del glorioso S. Fructos" ${ }^{29}$. Alli permanecieron durante años, mientras duró la ocupación musulmana de la Península, bajo la tutela de los monjes de Santo Domingo de Silos, que poseían el privilegio, dado por Alfonso III (866-910), de la Casa y Priorato de San Fructos; privilegio que les fue ratificado por su bisnieto, Alfonso VI (1072-1109), una vez que éste recuperó el territorio de la ciudad de Segovia y Sepúlveda donde se ubicaba dicho priorato. Posteriormente, en tiempos de Doña Urraca(1109-1126), el obispo Don Pedro de Segovia, con el apoyo del cabildo catedralicio, procura el traslado de las reliquias santas a la ciudad, pero se topa con la oposición del abad de Silos (Don Fortunio). El obispo acude al arzobispo de Toledo (Don Bernardo) buscando su intercesión en el asunto, aduciendo para ello diversas razones que justifican el traslado. Las dos principales que se señalan son, en primer lugar que las reliquias serían más veneradas en la

\footnotetext{
27 Consigno en el título de este apartado del estudio el sustantivo calificador que define el carácter especifico de los santos tratados: confesor para San Fructos, y mártir para sus hermanos. Dentro de la categorización de los santos cuando se habla de "mártir" (utestigo", en sentido etimológico): “Es que el cristiano que confiesa su fe en Jesús hasta la muerte da testimonio del señorio de Cristo" (MARTIMORT, A.G., La Iglesia en oración. Introducción a la liturgia. Barcelona, 1992, pág. 1002); mientras que «confesor» se designaba inicialmente a aquéllos que habiendo sufrido de alguna manera por su fe (exiliados, atormentados, prisioneros, etc.) no habian llegado a perder la vida; aunque, posteriormente, también fueron asimilados en esta categoría los ascetas y las vírgenes por profesar formas superiores de ascesis y, asimismo, los obispos, en principio por pertenecer a alguna de las tres primeras categorias precedentes, aunque paulatinamente se fueron integrando también en función de su ejemplar oficio.

${ }_{28}$ No sé si ha habido algún traslado posterior. En mis lecturas no he encontrado ninguno más; $y$ es de suponer que, una vez situadas en la catedral, no habrian de sufrirlo.

${ }_{29}$ Orche, J. de..., Historia de la vida del glorioso S. Fructos..., pág. 100 bis.
} 
ciudad ${ }^{30} ; \mathrm{y}$, en segundo, que en la situación presente corren peligro de ser profanadas por los musulmanes ${ }^{31}$. Finalmente, el abad de Silos accede, a petición del arzobispo, a entregar al cabildo los cuerpos de los santos o, al menos, una parte "buena y razonable de cada uno dellos" 32. El obispo y el cabildo van a San Fructos y convencen definitivamente al abad, que aún tenía ciertas reticencias, de la conveniencia del traslado con las razones anteriormente referidas. De esta manera, en el año de 1125 se produce el traslado de parte de las reliquias de los tres santos ${ }^{33}$; que serán llevadas a Segovia por el obispo y los prebendados que le acompañaban, todos "muy contentos, aunque no tanto como ricos, por traer consigo un thesoro de tanta estima y precio" ${ }^{34}$. Los restos sagrados serán depositados en un altar de una capilla situada a mano derecha del altar mayor, dedicada anteriormente a Santiago. A partir de este momento "començo nuestro Señor a hazer muchos milagros, por los merecimientos del glorioso S. Fructos, y de sus dos Santos hermanos, con los que a ellos se encomendaran, y les pedian su divino favor" ${ }^{35}$. Una vez que las reliquias están en la ciudad de Segovia, en el primer sínodo de este obispo se establece la festividad de San Fructos el día 25 de octubre, fecha de la muerte del santo; y la de san Valentín y Santa Engracia en el día siguiente; aunque esta segunda festividad desaparece en el Breviario de Pio V de 1568.

Llegados a este punto, parece pertinente resumir cómo quedaron repartidas las reliquias, y centrarnos en la suerte de las que quedan en

30 Esta razón, que se puede traducir como mantenimiento y estimulación del culto al santo, parece haber sido expresada en otros casos de traslado de reliquias, v.g., en la traslación de San Segundo, patrón de Ávila, desde su modesta ermita a la catedral (v. CATEDRA, M., Un santo para una ciudad. Barcelona, 1997. pág. 56-57)

31 Como señala Maria CAtedra (op. cit. pág. 55, n. 36), «La traslación de cuerpos santos parece haber sido una práctica frecuente especialmente en la península bajo la amenaza de que estos cuerpos pudieran ser mancillados por los moros".

No estaría de más considerar que otra motivación posible del obispo fuese de carácter crematístico, o la obtención de las limosnas dadas al santo.

32 Orche, J. de, Historia de la gloriosa vida de S. Fructos, pág. 133 bis.

33 En lo que respecta a este traslado hay una divergencia entre las noticias que de él nos da Juan de ORCHE y las que nos han llegado de mano de Diego de ColmENARES. Si bien ambos autores coinciden en fechar la traslación en el año 1125, el primer autor erróneamente la sitúa en el reinado de Alfonso VIII (1158-1214), mientras que Colmenares la ubica en el reinado de Doña Urraca (1109-1126), datación que parece más acertada. En vista de las discordancias, he optado por seguir la descripción de ORCHE, pero sin poder admitir como válido el argumento de la carta de petición que supuestamente manda el obispo al «Rey Don Alonso" (OrCHE, J. de, Historia de la vida del glorioso $S$. Fructos..., pág. 136) pidiéndole su favor para la traslación. Aunque, cabe la posibilidad de que tal carta fuese mandada a la reina Urraca; en todo caso esto último es una conjetura.

${ }_{34}$ Orche, J. de, Historia de la vida del glorioso S. Fructos, pág. 139 bis. Tras esta afirmación se puede ver el sentido más material de las reliquias, el prestigio que daba su posesión.

35 ORCHE, J. de, Historia de la gloriosa vida de S. Fructos...., pág. 140. 
Segovia. En este sentido, parte de los cuerpos santos se depositan en la catedral de esta ciudad; otra queda en San Fructos; las cabezas de San Valentín y Santa Engracia permanecen en Caballar; y, finalmente, en Santo Domingo de Silos quedan un dedo de San Fructos y la mano derecha de San Valentín, que tiene anillos, lo cual denota su posible dignidad de obispo.

\section{VICISITUDES POSTERIORES}

Las reliquias de la catedral se pierden de vista durante los años siguientes debido a la muerte del canónigo que conocía el secreto de su paradero. Pero, tras los ayunos y penitencias del obispo Juan Arias de Ávila (accede a esta prelacia en 1461), se encuentra el lugar donde se guardaban; produciéndose la milagrosa curación del cantero (Juan de Toro) que topa con ellas ${ }^{36}$. Esta maravilla, junto con otras señales (olor de fragancia suave, que es un claro índice de santidad; y otras no especificadas) ${ }^{37}$, demuestra la autenticidad del hallazgo. Los restos santos serán metidos por mandato del prelado Don Juan Arias de Ávila en una arca y se sacarán en procesión solemne por toda la ciudad "para que santificase las casas y moradas de los vecinos" ${ }^{38}$. Tras la procesión, las reliquias son llevadas de regreso a la catedral, donde permanecerán durante muchos años en un arca a la vista de los fieles, para fomentar su devoción y permitir que den consuelo a los que se acercasen a pedir su divino favor.

Con el pasar del tiempo, a la par que va aumentando la fama milagrera de los santos, se construye una capilla propia para las reliquias que permanecian en el ara dedicada a Santiago, situada donde se encontraba dicho altar. Las reliquias se repartieron entre el arca, donde permaneció la mayor parte de las mismas, y una caja "en que estaban una espalda, o cadera, y una quijada de señor San Fructos" ${ }^{39}$, que se colocó, por su

\footnotetext{
36 Como las reliquias se encuentran el veintiuno de noviembre, el obispo sitúa las fiesta del Santo en este dia, pero posteriormente vuelve al veinticinco del mes de octubre.

37 Todos los prodigios que se van produciendo en torno a los restos sagrados van configurando la leyenda de San Fructos, hecho que justifica de forma paulatina la devoción que le es debida al santo, asi como crea la conciencia de que es buen abogado intercesor para la comunidad. No obstante, cuando realmente aparece una conciencia perenne del vinculo de la ciudad con el santo, lo que podria verse como un sentimiento de filiación, es posteriormente, a raíz de la actividad taumatúrgica del santo cuya devoción está consuetudinariamente establecida.

38 ORCHE, J. de, Historia de la gloriosa vida de S. Fructos..., pág. 174 bis. En la cita se puede intuir la cualidad profiláctica (en un sentido lato)que se le atribuia a las reliquias de un santo.

39 Orche, J de, Historia de la gloriosa vida de S. Fructos...., pág. 175 bis.
} 
parte, en otro hueco de la pared de la capilla, procurando su mayor accesibilidad para poder sacar manualmente los santos restos y ofrecerlos a adorar y tocar.

Las reliquias permanecieron durante muchos años en la capilla construída por Juan de Ávila, hasta que los alborotos causados por las revueltas comuneras - que obligaron a la comunidad catedralicia a abandonar la seo segoviana y refugiarse en el convento de Santa Clara-, y por el temor de que pudiesen sufrir algún daño los sagrados cuerpos, se decidió que lo mejor era proceder a su traslado a los Alcázares, donde permanecerian a buen seguro. Una vez que los disturbios fueron sofocados, el Deán y el Cabildo, que permanecian en el convento de Santa Clara, donde se comenzó a edificar la nueva catedral (ya que la antigua había quedado muy deteriorada), procuraron trasladar las reliquias desde su antigua localización en el Alcázar hasta el lugar donde ellos se encontraban. No obstante, toparon con la oposición del obispo (llegó a amenazar con la excomunión si se procuraba el traslado), así como con la del Conde de Chinchón, señor del Alcázar, y de su alcaide. Finalmente, a pesar de los obstáculos, la voluntad del traslado se impondría tras la muerte del conde y el alcaide; debido a que la condesa de Chinchón, doña Teresa de la Cueva, que deseaba trasladar su residencia a su condado, creyó más conveniente que las reliquias de los santos patrones de Segovia estuviesen allí (en el convento de Santa Clara) donde recibirían una mayor devoción y un mejor cuidado, en lugar de quedar en el Alcázar, donde no se tendría acceso a su culto ${ }^{40}$. En esta nueva situación, el obispo se avino con los deseos del Deán y el Cabildo, alzando "las censuras y excomunion" 4 " inicialmente impuestas, y otorgando su licencia, el veinticuatro de octubre de 1522, para que se procediese al traslado de las reliquias de los Alcázares junto con un crucifijo y un imagen de la Virgen a los que se profesaba una gran devoción.

TRASLACIÓN DE LAS SANTAS RELIQUIAS Y SAGRADOS HUESOS DE SAN FRUCTOS, SAN VALENTINN Y SANTA ENGRACIA DESDE LOS ALCÁZARES A LA IGLESIA DE SANTA CLARA

El obispo dio su beneplácito para la traslación de las reliquias de los santos patrones, del santo crucifijo y de la imagen de Nuestra Señora a la

Vid. supra. n. ${ }^{\circ} 30$.

41 OrChE, J. de, Historia de la vida del glorioso S. Fructos..., pág. 185. 
Iglesia de Santa Clara, donde - como ya se ha dicho - se encontraba a la sazón la Catedral segoviana, expresando su deseo de que todo fuese organizado de acuerdo con la solemnidad requerida por la ocasión, y dando al respecto las directrices que consideró pertinentes. En primer lugar mandó que se procurase un sitio digno y adecuado («decente» es la palabra que usa Orche) para la veneración y custodia de las sagradas reliquias e imágenes. A continuación señaló la conveniencia de que todas las "religiones" ${ }^{42}$ (refiriéndose a las órdenes religiosas), la justicia, los regidores, las cofradías con sus cruces de parroquias y «todo el otro clero de la ciudad" (léase, el clero secular) ${ }^{43}$ asistiesen con la "devocion y authoridad que tal caso requería. Y para mas despertar la devocion de los fieles, y los animos, para acompañar a la procesión, concedio su señoria cuarenta dias de perdon y indulgencia a los que acompañassen la procession, y viniessen con los sagrados huesos. Mando asimesmo absolver por tres dias todos los excomulgados, que en la ciudad vuiesse, porque dignamente pudiessen acompañar las santas reliquias, y ganar los perdones" ${ }^{44}$.

El Cabildo y el Deán, con la licencia del obispo, y conforme a sus mandatos, propusieron todo to necesario, con extremada rapidez y diligencia, para que la procesión solemne de traslado se llevase a cabo el día siguiente, veinticinco de octubre, coincidente con la festividad de San Fructos.

\section{LA PROCESIÓN}

El sábado veinticinco de octubre de 1522, "acabada la hora de tercia, estando juntas todas las cruces» ${ }^{45}$, la ciudad de Segovia está preparada para marchar en procesión, "cada uno en su lugar con mucho concierto y orden "46: las cofradias con cirios encendidos, seguidas de las Órdenes con sus prelados; tras éstas el clero secular, y "hallandose presentes, el Licenciado Andres de Camargo Prouisor, el corregidor, y sus tenientes, algunos Regidores, y muchos Caualleros, hidalgos, mercaderes, y ciudadanos, y muchas señoras y dueñas y otra gente popular de esta ciudad, y arrabales $y$ de otras partes".

\footnotetext{
42 ibid. pág. 185.

43 bidem, id.

44 Ibidem. Aquí podría ser apreciable cierto interés de la Iglesia de fomentar la adhesión masiva de las masas a una religiosidad opulenta y exterior, que procura eliminar la disensión social. No obstante, este tipo de política religiosa es más propio de la Iglesia contrarreformista.

45 ORCHE, op. cit. pág. 186 bis.

46 lbid., pág. 187. Vid. Supra, ${ }^{\circ}{ }^{\circ} 10$
} 
Esta primera descripción general y poco detallada que Orche da de la composición de la procesión, en la que va mencionando los diferentes segmentos integrantes de las misma - con la única salvedad del licenciado, al que cita con nombre y apellido, señalando su tratamiento o condición ${ }^{47}$, permite advertir ya una perfecta gradación jerárquica, o, si se prefiere, un orden de prelación, en la que las corporaciones (tanto religiosas como laicas) se sitúan en la cúspide de una estructura social que, a modo de delta, se va difuminando y perdiendo intensidad al término de la desembocadura, donde entran categorias sociales tan genéricas y poco definidas como ciudadanos, señoras y gente popular. Es de notar la diferenciación entre sexos y que, en última instancia, se menciona a los foráneos, restándoles claramente peso en el evento; lo cual es muy comprensible si consideramos que «la procesión sería como un idioma tradicional de la sociedad urbana" ${ }^{48}$ en el que se muestra la identidad de la ciudad ${ }^{49}$, de la que no son parte integrante los forasteros que coyunturalmente llegan a ver la procesión (un caso distinto eran los foráneos con residencia permanente en la ciudad) ${ }^{50}$.

A continuación Orche centra su atención en las diferentes dignidades eclesiásticas que acompañan a la procesión, realizando un listado en el que refiere nombre y vestimenta (que expresa cargo y condición) de la persona: Don Pedro Vaca, Deán, vestido de presbítero, Pedro de Castro, diácono, Gabriel Muñoz, subdiácono, a los que siguen canónigos con diferentes indumentarias (de presbiteros, de diáconos y de acólitos). Es en definitiva el Deán junto al Cabildo catredalicio quien, como a continuación señala Orche, sale de Santa Clara encabezando la marcha que se dirige a los Alcázares, pasando por la calle del Almuzara, y que, al igual que la de la Canongia y el resto del itinerario, "estaua muy aderezadas y entoldadas de mucha y rica tapizeria, $y$ atrechos ciertos altares y oratorios deuotos" ${ }^{11}$. Aunque la descripción de los ornamentos colocados a lo largo del

\footnotetext{
47 En francés se expresaría con el término de qualité (Vid. DARNTON, R., La gran matanza de gatos $y$ otros episodios en la historia de la cultura francesa., F. C. E., México, 1994. Cap. III. Passim.), que nosotros traducimos por cualidad, término que consideramos más abierto a la anfibología que cualquiera de los dos propuestos, pareciéndonos más concreto el primero, aunque menos incisivo y definitorio que el de condición, que conjuga el sentido de tratamiento con el de cualidad (si recurrimos al diccionario, nos da como sinónimos de condición: clase, categoría y cualidad, etc. ;mientras que de tratamiento: título, dignidad y cortesía. En mi opinión es claramente perceptible el matiz aristocrático de este segundo término).

48 Darnton, R. La gran matanza de gatos ... México, 1994. pág. 118.

49 Esta capacidad de la procesión de expresar y fomentar la identidad de la ciudad ya está expresada por Natalie Zemon Davis: "These processions could dramatize the city's identity and give protection to the body af the town (...)». ZEMON DAVIS, $N$ «The sacred and the body social in sixteenth-century Lyon». Past and Present, n. ${ }^{\circ}$ 90, February, 1981.

50 Sobre estos temas se apuntan algunos argumentos en ZEMON DAVIS, N., Op. cit.

5. OrCHE, J. de, Historia de la vida del glorioso S. Fructos..., pág. 187.
} 
itinerario procesional es prácticamente nula, no es óbice para percibir que se asemejaba a la norma general de las procesiones religiosas en las que los balcones se aderezaban con tapicerías y crespones, y se colocaban altares en diferentes puntos estratégicos del recorrido.

Cuando la marcha llega a la puerta levadiza de los Alcázares las cofradías se detienen, quedando detrás la clerecía, las Órdenes y el resto de la procesión, de forma que únicamente entran a los Alcázares, "porque no vuiesse alguna confusion" ${ }^{52}$, el Deán y sus ministros con los cantores y algunos menestriles, más los que "auian de llevar las hachas" 53 así como los superiores de las órdenes, cierto número de licenciados, algún regidor, un protonotario, y algunas otras personas. En definitiva, las más altas dignidades de las distintas corporaciones y los que iban a tener una función específica dentro del ceremonial (notarios, cantores, menestriles y portadores de hachas). A ellos se debe sumar la presencia de Juan de Pantigofo y Gonzalo Martínez de Villamayor, racioneros, y notarios públicos por la autoridad Apostólica, el bachiller Diego de Guevara, notario público, con número en la Audiencia Eclesiástica y secretario del Deán y el Cabildo, que serán los que dejen constancia escrita de lo allí acontecido y encontrado.

Primero se toma juramento a personas que hayan estado próximas a las reliquias desde que se sacaron de la antigua catedral hasta el momento presente, y se escucha su testimonio. Luego se prosigue con la apertura pública del arca donde se contienen las santas reliquias, encontrándose "ciertos paños de seda y cendal, dentro de los cuales parecieron vna razonable y buena parte de ciertos huessos de cuerpos humanos de do salio muy grande fragancia de suavisimo olor" ${ }^{54}$, claro signo de santidad, que movió a todos a la reverencia y a algunos de los allí presentes a tocar con rosarios y otros objetos «a los sagrados cuerpos con grande reverencia, devocion y acatamiento, y con mucha efusion de lagrimas» ${ }^{55}$. En

\footnotetext{
52 Ibidem. bis. Es de suponer que se evita el tumulto para que las reliquias no sufran algún percance.

${ }_{53}$ Ibid. pág. 188. Hacha: Vela de cera, grande y gruesa, de figura por lo común de prisma cuadrangular y con cuatro pábilos. // (...). Diccionario de la Lengua Española. Madrid, Real Academia Española, 1992

54 Ibid. pág. 192.

55 Ibia. bis. Se procura la contaminación del objeto con la esencia taumatúrgica de la reliquia. Esta práctica parece posible vincularla a los orígenes del culto a las reliquias en la cristiandad occidental (a diferencia de la oriental), que no admitía la separación de ninguna parte del cuerpo santo ni el contacto con él ni su traslado ("Esta situación cambiaré en Roma en el siglo VII al trasladarse los restos de los mártires al centro de la ciudad desde las basílicas suburbanas: GARCIA RODRIGUEZ, C. El culto de los santos e la España romana y visigoda, Madrid, C.S.I.C., 1966, pág. 365), por lo que se utilizaban reliquias de contacto , brandea, que "se obtienen mediante la colocación de paños sobre
} 
el momento de la aparición de las reliquias los cantores entonan Te Deum laudamus y los menestriles tañen sus instrumentos "muy dulcemente" 56 .

Llegados a este punto, se procede a sacar del Alcázar los santos cuerpos, llevados por cuatro presbíteros, que son seguidos por la imagen de la Virgen y el crucifijo, situado detrás de ésta, portados, de igual forma, cada uno por cuatro personas. Las reliquias y la imagen son llevados en andas entoldadas, mientras que el crucifijo es cubierto por un "paño de rico brocado sobre seys varas que lleuaron seys personas principales, quitados los uonetes con mucho acatamiento, delante $y$ al rededor de todo ello veynte personas de honra con veynte hachas de cera ardiendo" ${ }^{57}$. Delante de las reliquias y las imágenes se va incensando. $Y$ el Deán irá con la espalda de San Fructos cogida con unas ricas toallas. Se procede a salir con mucho orden y concierto, siendo flanqueada la procesión por veinticinco alabarderos que esperan en la última puerta del Alcázar, donde se cumple, entre el alcaide del mismo y un notario, el formalismo de entrega en el que se refieren milagros realizados por el santo mientras estuvo en los Alcázares (sanación de una quebradura por contacto con su espalda). A continuación se pasa el puente levadizo, "donde estaban las cruces (se refiere a las parroquias) con las de las cofradias, y el organista de la Yglesia (entiéndase la catedral) comenzó a tañer luego unos organos portatiles que alli estauan: los cantores cantando (demas del Te Deum laudamus) otras cosas de deuocion: y los menestriles continuando lo que tañian ${ }^{58}, \mathrm{y}$

la tumba del santo, y resultan tan virtuosas como si se tratase del cuerpo entero" (BOUZA ÁLVAREZ, J. L., Religiosidad contrarreformista y cultura simbólica del barroco. C.S.I.C., Madrid, 1990), "(d)e este modo se satisfacia la devoción de los peregrinos que acudían a las basilicas de los mártires y podian así llevarse un signo visible de su protección" (Garcia Rodriguez, C., op. cit. pág. 366.). En cualquier caso la idea de contaminación parece ser inherente a las creencias humanas en general. Es un concepto ya señalado por Sir James George FrAZER (que si bien ha sido criticado (vg. por Wittgenstein que, más interesado por los significados de los misterios de los hechos, que nacen de la naturaleza misma del ser humano, reprocharía la actitud metodológica de Frazer, centrada en la acumulación de datos, en la referencia objetiva, en la que él incluiria el significado de los hechos) con mayor o menor tino, en nuestra opinión tuvo ciertos aciertos, o al menos apuntó algunas observaciones de utilidad; no obstante desde nuestra perspectiva de historiador, y no de antropólogo, no debemos juzgar su figura), quien en La rama dorada (Madrid, F.C.E.. 1993) ya señalaba que existe en diferentes culturas la idea de que «(...) las cosas inanimadas (...) pueden difundir beneficios o daños a su alrededor de acuerdo con su propia naturaleza intrínseca (...)" (pág. 57). Aunque, creemos, no hace falta recurrir a supuestos ejemplos científicos para fundamentar esta idea de la contamina ción, la cual se hace perceptible para cualquiera de forma empírica: la cosiumbre "supersticiosa" de tocar madera es un ejemplo de creencia en la virtud de tocar este material; pero un ejemplo que se inscribe en el sentimiento religioso de los individuos es acto movido por una puisión intima de tocar o besar una imagen sagrada, creyendo que nos sanará o concederá algún tipo de favor; basta con asistir a una iglesia y preguntar a algún beato.

56 Ibidem.

57 lbidem págs. 193 bis.

58 Ibid. págs. 195 bis, 196. 
la procesión reanuda la marcha ${ }^{59}$ manteniendo el orden de venida, acompañada por un cortejo devoto de hombres, mujeres y niños que suspiran y derraman lágrimas ${ }^{60}$. En el trayecto se detiene la procesión en el monasterio de nuestra Señora de la Merced, donde se introducen las reliquias e imágenes a su iglesia y, una vez se ha hecho oración, se sale en dirección a la Iglesia de Santa Clara. Llegados a dicha iglesia, se coloca el arca de las reliquias sobre un altar, la imagen sobre una mesa y el crucifijo cercano a ésta, todo lo cual es rodeado de numerosas velas encendidas.

A continuación se permitió la entrada de cuanta gente cupo en la iglesia y se celebró una Misa en la que el oficiante dedicó su sermón, "bien aplicado al acto y traslacion de las santas reliquias y sagrados huesos" ${ }^{61}$, a referir algunos milagros hechos por el Señor en Segovia, por "los merecimientos y intercesion destos gloriosos Santos" ${ }^{62}$. Durante el resto del día hubo una constante afluencia de gentes anhelantes de venerar y tocar las reliquias (la espalda y la quijada de San Fructos), o de introducirlas en un agua con la que se lavarían para sanar sus heridas.

Finalmente, en un día posterior, las reliquias serían colocadas provisionalmente en el altar mayor, hasta que fueron definitivamente depositadas en una capilla que se fundó bajo su advocación, "donde han estado y estan agora de presente: y de tiempos a tiempos haze el Señor diversos milagros por los merecimientos destos gloriosos Santos, con que se refresca la devocion de los fieles, y es dada gloria a Dios, el qual es glorioso en sus santos" ${ }^{63}$.

Aquí concluye el proceso: la ciudad en procesión se ha visto en su santo, ha vivido en su santo; y su santo se ha visto en la ciudad, con la que aún sigue viviendo; es la comunión de identidades compartidas.

\footnotetext{
59 Aproximadamente, a esta altura de su relato ORCHE señala cómo la procesión se produjo sin ningún alboroto ni disturbio y cómo la traslación de las reliquias hicieron que la epidemia de peste, de la que hasta ahora no habíamos tenido noticia, cesó; recomendando ante tal prodigio que siempre que hubiera brotes de pestilencia se sacaron en procesión las reliquias de estos santos (esto es ejemplo de la asimilación del santo a la acción profiláctica y sanadora).

60 Se aprecia que hay un sentimiento beatífico y devocional generalizado, cotejándolo con las lágrimas y acatamiento y devoción que anteriormente se ha referido que tuvieron los privilegiados que entraron en los Alcázares. Vid Supra, n. ${ }^{\circ} 10$.

61 Ibid. pág. 197 bis.

62 Ibidem. Vid. Supra. n. 26.

63 Ibid. págs. 198-199. La obra de ORCHE refiere a continuación numerosos milagros hechos por san Fructos una vez muerto (prodigios post morten).
} 